\title{
NILAI RELIGIUS DAN NILAI SOSIAL DALAM MATERI PEMBELAJARAN SASTRA (CERPEN) PADA BUKU TEKS BAHASA INDONESIA SMP/MTS KELAS VIII
}

\author{
Eko Purwandi, Emi Agustina, dan Amril Canhras \\ Program Studi Pendidikan Bahasa Indonesia \\ Jurusan Pendidikan Bahasa dan Seni \\ FKIP Universitas Bengkulu \\ ekopurwandi34@gmail.com
}

\begin{abstract}
Abstrak
Tujuan penelitian ini untuk mendeskripsikan nilai religius dan nilai sosial dalam materi pembelajaran sastra (cerpen) pada buku teks bahasa Indonesia SMP/MTs kelas VIII. Jenis penelitian ini adalah penelitian kualitatif, sedangkan metode yang digunakan adalah metode deskriptif dan juga pendekatan model analisis konten. Data penelitian ini adalah tiga cerpen yang ada di Buku Teks Bahasa Indonesia Wahana Pengetahuan SMP/MTs kelas VIII, yaitu cerpen "Nasehat Untuk Anakku, Emak dan Sepotong Roti, Ke Luar Negeri Untuk Mengembalakan Sapi". Dari hasil analisis yang dilakukan terhadap ketiga cerpen pada buku teks bahasa Indonesia SMP/MTs kelas VIII maka diketahui bahwa nilai religius adalah suatu pandangan yang berhubungan manusia dengan Tuhan terdiri dari; syukur, sabar, tawadhu, tawakal, ikhtiar, dan istiqomah. Nilai religius tersebut mencerminkan akhlak sesorang yaitu akhlak kepada Allah SWT, akhlak kepada orang tua, dan akhlak dalam menerima ketentuan Allah. Hal ini baik untuk siswa menerapkannya dalam pembelajaran di sekolah maupun kehidupan sehari-hari. Dan nilai sosial adalah suatu kesadaran yang memiliki kualitas perilaku, pikiran, dan karakter yang dianggap masyarakat baik, terdiri dari; peduli keluarga, peduli sesama, jujur, kerja keras, mandiri, dan sopan santun. Nilai-nilai sosial yang terkandung dalam cerpen tersebut berguna dalam menanamkan sikap sosial pada peserta didik. Nilai pada cerpen tersebut dapat membantu dalam membentuk karakter peserta didik.
\end{abstract}

\section{Kata Kunci: Nilai religius, nilai sosial, teks cerpen, buku teks}

\begin{abstract}
This research aims to describe religious and social values in literary learning materials (short story) on the textbook of Bahasa Indonesia SMP/MTs class VIII. This kind of research was a qualitative research, while the method used was descriptive method and content analysis model approach. The data in this research was by taking three short stories existed in the Buku Teks Bahasa Indonesia Wahana Pengetahuan SMP/MTs class VIII, they were "Nasehat Untuk Anakku, Emak dan Sepotong Roti, Ke Luar Negeri Untuk Mengembalakan Sapi". From the result of analysis which is done towards the three short stories on the textbook of Bahasa Indonesia SMP/MTs class VIII, it is known that religious value is a view related to the human and the God consisted of; fortunate, patient, inferiority, surrender, endeavor, and consistent. Those religious values reflect someone's attitude, which is the attitude towards Allah SWT, parents, and in accepting Allah's decision. This is good for students to implement in the school learning or daily activities. Then, social value is an awareness that has quality of behavior, thinking, and character which are considered good by the communities, consist
\end{abstract}


of; caring family, caring each other, honest, hardwork, independent, and polite. The social values contained in the short stories are useful in infusing social attitudes on the learners. The values in the short stories may help to build the learners' character.

\section{Keywords: Religious value, social value, short stories, textbook}

\section{PENDAHULUAN}

Pembelajaran Bahasa Indonesia merupakan suatu proses belajar mengajar yang sangat berkaitan erat dengan pembelajaran sastra. Pembelajaran sastra merupakan komponen yang sangat penting dan mendukung keberhasilan anak dalam memahami materi-materi di mata pelajaran Bahasa Indonesia, khususnya materi mengenai sastra seperti prosa, puisi, dan drama. Pada dasarnya, karya sastra sangat bermanfaat bagi kehidupan karena dapat memberi kesadaran kepada pembaca tentang kebenaran-kebenaran hidup meskipun dilukiskan dalam bentuk fiksi.

Pada dasarnya, karya sastra sangat bermanfaat bagi kehidupan karena dapat memberi kesadaran kepada pembaca tentang kebenaran-kebenaran hidup meskipun dilukiskan dalam bentuk fiksi. Seperti yang disampaikan oleh Nurgiyantoro (2010:3), fiksi menceritakan berbagai masalah kehidupan manusia dalam interaksinya dengan lingkungan, diri sendiri, serta interaksinya dengan Tuhan. Walaupun berupa fiksi, tidak benar jika sebuah karya sastra dianggap sebagai hasil kerja lamunan belaka, sebab karya sastra merupakan sebuah hasil penghayatan dan perenungan secara intens, perenungan terhadap hakikat hidup dan kehidupan, yang semuanya dilakukan dengan penuh kesadaran dan tanggung jawab.

Sastra merupakan karya dan kegiatan seni yang berhubungan dengan ekpresi dan penciptaan, yang selalu tumbuh dan berkembang hasil-hasilnya. Menurut Damono (dalam Jabrohim, 2012:215) berpendapat bahwa sastra menampilkan gambaran kehidupan, dan kehidupan itu sendiri adalah suatu kenyataan sosial.

Definisi cerpen dalam Kamus bahasa Indonesia (2008:956) adalah karangan pendek (kurang dari 10.000 kata) yang memberikan kesan tunggal dan memusatkan diri pada satu tokoh dalam satu situasi. Cerita pendek adalah cerita fiksi yang bentuknya pendek dan ruang lingkup permasalahannya menyuguhkan sebagian kecil saja dari tokoh yang menarik perhatian pengarang dan keseluruhan cerita memberi kesan tunggal.

Pembelajaran pada kurikulum 2013 yang berlaku saat ini adalah pembelajaran berbasis teks. Berkaitan dengan hal tersebut, untuk jenjang pendidikan menengah kelas VIII Bahasa Indonesia ditempatkan sebagai bahan untuk mengekspresikan perasaan dan pemikiran. Selain itu, sebagai bagian dari kurikulum 2013 yang menekankan pentingnya keseimbangan kompetensi sikap, pengetahuan dan keterampilan, kemampuan berbahasa yang dituntut tersebut dibentuk melalui pembelajaran berkelanjutan.

Dalam kurikulum 2013, siswa dibekali dengan buku pegangan siswa dengan judul buku Bahasa Indonesia Wahana Pengetahuan SMP/MTs Kelas VIII. Salah satu materi di dalam buku tersebut adalah teks cerpen. Di dalam teks bahasa Indonesia SMP/MTs kelas VIII terdapat tiga cerpen, yaitu cerpen Nasehat untuk Anakku karya Motinggo Busye, Emak dan Sepotong Roti karya Caswati dan dan cerpen Ke Luar Negeri untuk Mengembala Sapi Karya Abadi Simanjutak.

Cerpen "Nasehat Untuk Anakku" adalah karya ke-9 Motinggo Busye. Cerpen 
ini menceritakan tentang banyak berubahnya keadaan dunia, perjuangan hidup dan berbagai nasehat dari ayah untuk anaknya. Kemudian cerpen "Emak dan Sepotong Roti" merupakan salah satu judul hasil karya sastra Caswati, cerpen ini menceritakan tentang kisah perjuangan seorang Emak dalam memenuhi kebutuhan keluarganya. cerpen selanjutnya, yaitu cerpen " Ke Luar negeri Untuk Mengembalakan Sapi" karya Abadi Simanjutak yang memuat sebuah cerita seorang anak yang memanfaatkan liburannya dengan membantu keluarganya. Dengan melihat persoalan cerpen tersebut, peneliti beranggapan bahwa dengan mengetahui nilai-nilai yang terdapat dalam cerpen buku teks tersebut, maka dapat dijadikan sebagai acuan untuk mampu berbuat positif di masyarakat.

Nilai atau value (bahasa Inggris) atau valere (bahasa latin) berarti berguna, mampu akan berlaku dan nilai-nilai kehidupan menurut Sujarwa (2010:181) adalah norma-norma yang berlaku dalam masyarakat atau prinsip-prinsip hidup yang menjadi pegangan seseorang dalam hidupnya, baik sebagai pribadi maupun sebagai warga negara. Religius diambil dari bahasa Latin relego, dimaksudkan dengan menimbang kembali atau prihatin tentang (suatu hal). religi merupakan kesadaran yang menggejola secara mendalam dalam lubuk hati manusia sebagai human nature. Kata "sosial" berarti hal-hal yang berkenaan dengan masyarakat /kepentingan umum. Nilai sosial merupakan hikmah yang dapat diambil dari prilaku sosial dan tata cara hidup sosial. Hal ini selaras dengan yang dikemukanan oleh Youpika (2016: 57) dalam hasil penelitiannya menyatakan bahwa dilihat dari nilai yang terkandung di dalamnya, karya sastra dapat dimanfaatkan sebagai materi pembelajaran sastra di sekolah.
Hal-hal yang fundamental terkait dengan penelitian di dalam ahlak antara lain (1) Akhlak Kepada Allah SWT; (2) Akhlak kepada kedua orang Tua; (3) Akhlak dalam menerima ketentuan Allah. Dalam penelitian ini nilai religius diekplisitkan dalam indikator penelitian yang bersumber acuan dari buku pendidikan karakter perspektif islam, yaitu: nilai religius syukur, sabar, tawadhu, tawkal, ikhtiar, dan istiqomah. Adapun nilai sosial dalam penetian yang digunakan diekplisitkan dalam indikator yang bersumber acuan dari buku revisi kurikulum 2013 implementasi konsep dan penerapan, yaitu: peduli keluarga, peduli sesama, jujur, kerja keras, mandiri, dan sopan santun. Berdasarkan latar belakang tersebut, maka peneliti mencoba untuk mendeskripsikan nilai religius dan nilai sosial yang terkandung di dalam cerpen pada buku teks bahasa Indonesia SMP/MTs kelas VIII. Untuk itu peneliti mengambil penelitian dengan judul Nilai Relegius dan Nilai Sosial dalam Materi Pembelajaran sastra (Cerpen) pada Buku Teks Bahasa Indonesia SMP/MTs Kelas VIII.

\section{METODE}

Metode yang digunakan dalam penelitian ini adalah metode deskriptif kualiatif, dengan pendekatan analisis isi. Sumber data dalam penelitian ini adalah teks cerpen yang terdapat pada Buku Teks Bahasa Indonesia Wahana Pengetahuan SMP/MTs Kelas VIII. Data pada penelitian ini berupa nilai religius dan nilai sosial yang ada dalam teks cerpen tersebut. Penelitian yang dilakukan ini menggunakan kriteria yang tidak keluar dari rujukan yang digunakan yaitu indikator pada kurikulum 2013. Sumber rujukan ini diambil dari buku pendidikan karakter perspektif islam dan buku revisi kurikulum 2013 implementasi konsep dan penerapan.Teknik pengumpulan data dalam penelitian ini dilakukan dengan cara dokumentasi. 
Langkah-langkah yang dilakukan dalam penelitian menganalisis data pada penelitian ini yaitu, membaca, mengidentifikasi, mengklasifikasi, menjabarkan, dan menarik kesimpulan.

\section{HASIL DAN PEMBAHASAN}

Cerita pendek adalah cerita fiksi yang bentuknya pendek dan ruang lingkup permasalahannya menyuguhkan sebagian kecil saja dari tokoh yang menarik perhatian pengarang dan keseluruhan cerita memberi kesan tunggal.Ada tiga cerpen yang terdapat pada buku teks bahasa Indonesia wahana pengetahuan SMP/MTs kelas VIII yaitu "Nasehat untuk Anakku" karya Motinggo Busye, "Emak dan Sepotong Roti" karya Caswati, dan "Ke Luar Negeri untuk Mengembalakan sapi" karya Abadi Simanjutak. Cerpen Nasihat untuk Anakku bercerita tentang kehidupan sang Ayah, beserta nasihat-nasihat yang diperuntukkan anaknya. Kemudian, cerpen Emak dan Sepotong Roti menceritakan kisah seorang ibu dan kedua anaknya di sebuah desa yang sedang mengalami kekeringan (kemarau panjang). Cerpen selanjutnya adalah cerpen Ke luar Negeri untuk Mengembalakan Sapi bercerita tentang tokoh saya yang merupakan keturunan blasteran dua Negara. Ibu tokoh Saya berasal dari Timor Leste, sedangkan bapak Saya berasal dari Indonesia dari suku Batak.

\section{Analisis Nilai Religius}

Dalam materi pembelajaran sastra (cerpen) pada buku teks bahasa Indonesia SMP//MTs kelas VIII yang telah dilakukan peneliti terhadap nilai religius, nilai-nilai religius yang tergambar di dalam materi cerpen tersebut bisa membantu membentuk karakter siswa yang berakhlak baik. Nilai-nilai religius yang tergambar mencerminkan akhlak yang baik bagi seseorang yaitu akhlak kepada Allah SWT, akhlak kepada orang tua, dan akhlak dalam menerima ketentuan Allah. Data yang tergambar sebagai nilai religius sudah memunculkan nilai yang mengarah ke acuan indikator dalam penelitian. Oleh karena itu cerpen-cerpen pada buku teks bahasa Indonesia SMP/MTs kelas VIII dapat berguna untuk siswa dalam membentuk kepribadian yang religius sesuai dengan tujuan yang tertuang di dalam kurikulu 2013 yaitu menjadikan manusia yang beriman, berakhlak dan betaqwa keapada Tuhan Yang Maha Esa. Hal ini merupakan sikap yang berguna bagi seorang siswa yang merupakan pelajar yang baru berusia remaja. Dengan cerpencerpen yang digunakan sebagai materi pembelajaran sastra tersebut dapat menumbuhkan sikap-sikap yang lebih religius lagi baik itu berguna bagi diri sendiri maupun orang-orang yang berada disekitarnya.

\section{Analisis Nilai Sosial}

Dalam materi pembelajaran sastra (cerpen) pada buku teks bahasa Indonesia SMP//MTs kelas VIII yang telah dilakukan peneliti terhadap nilai sosialnya untuk membentuk karakter siswa yang mempunyai sikap peduli keluarga, peduli sesama, jujur, mandiri, dan santun yang merupakan dari tujuan kurikulum 2013 saat ini baik untuk diimplementasikan. Cerpen-cerpen yang terdapat pada buku teks tersebut mengajarkan kepada siswa agar bisa berbuat lebih baik lagi dalam bersosialisasi terhadap diri sendiri maupun lingkungan sekitar. Hal ini contohkan dari setiap kutipan pada nilai-nilai sosialnya. Seperti tokoh Ayah yang memperdulikan orang-orang disekitarnya walaupun keadaan tokoh sang Ayah juga harus diperdulikan, tetapi beliau mengesampingkan kepentingan pribadinya agar orang yang berada di sekitarnya bisa bahagia. Selain tokoh tokoh Emak yangharus banting tulang bekerja untuk mencukpi kebutuhan kedua anaknya. 
Emak harus bekerja keras, selain menjadi seorang ibu tetapi Emak juga menjadi kepala rumah tangga sekaligus. Hal ini menggambarkan sikap sosial yang peduli keluarga, mandiri, dan pekerja keras. Selain itu juga pada cerpen Ke Luar Negeri Untuk Mengembalakan Sapi yang menceritakan perjalanan liburan seorang anak kecil yang membantu neneknya. Liburan yang dikemas dengan cara berbeda dimunculkan di dalam cerita pada teks cerpen tersebut, biasanya orang beranggapan bahwa berlibur artinya bertamasya, berjalan-jalan bersama keluarga ke tempat kreasi, atau bermaimain bersama teman-teman. Lain hal nya dengan tokoh saya dalam cerpen tersebut, tokoh saya membuat berliburan lebih berarti dengan membantu neneknya. Kebahagiaan yang didapatkan tokoh saya mempunyai arti yang sangat berguna untuk para siswa. Dengan membantu keluarga kita berarti kita sudah menanamkan sikap peduli keluarga, peduli sesama, mandiri, dan santun.

\section{PENUTUP}

\section{Kesimpulan}

Berdasarkan hasil penelitian yang telah penulis lakukan dalam cerpen buku teks "Bahasa Indonesia Wahana Pengetahuan SMP/MTs Kelas VIII" dapat disimpulkan bahwa nilai religius dan nilai sosial dalam materi pembelajaran sastra (cerpen) pada buku teks bahasa Indonesia SMP/MTs kelas VIII adalah sebagai berikut:

Nilai religius dalam materi pembelajaran sastra (cerpen) pada buku teks bahasa Indonesia SMP/MTs kelas VIII tergambarkan di dalam peristiwa melalui tokoh-tokoh dalam cerita. Nilai religius seperti nilai syukur, sabar, tawadhu, tawakal, ikhtiar dan istiqomah dapat kita pelajari dari beberapa kutipan dalam cerpen tersebut. Nilai religius syukur tergambar dalam cerpen Nasehat Untuk Anakku dan Ke Luar Negeri Untuk
Mengembalakan Sapi; nilai religius sabar dalam cerpen Nasehat Untuk Anakku dan Emak dan Sepotong Roti; tawadhu dalam cerpen Emak dan Sepotong Roti;tawakal dalam cerpen Nasehat Untuk Anakku dan Emak dan Sepotong Roti; ikhtiar dan istiqomah dalam cerpen Emak dan Sepotong Roti. Nilai religius tersebut mencerminkan akhlak sesorang yaitu akhlak kepada Allah SWT, akhlak kepada orang tua, dan akhlak dalam menerima ketentuan Allah. Hal ini baik untuk siswa teladani dan terapkan dalam pembelajaran di sekolah maupun kehidupan sehari-hari.

Nilai sosial dalam materi pembelajaran sastra(cerpen) pada buku teks bahasa Indonesia SMP/MTs kelas VIII tergambar dalam ketiga cerpen, yaitu cerpen Nasehat Untuk Anakku, Emak dan Sepotong Roti dan Ke Luar Negeri Untuk Mengembalakan Sapi; peduli sesama dalam cerpen Nasehat Untuk Anakku. Kemudian nilai sosial kerja keras dan mandiri tergambar di dua cerpen yaitu cerpen Emak dan Sepotong Roti dan Ke Luar Negeri Untuk Mengembalakan Sapi. selanjutnya nilai sosial peduli sesama dan jujur tergambar dalam cerpen nasehat Untuk Anakku. Nilai-nilai sosial tersebut membantu dalam menanamkan sikap sosial yang berguna untuk diri sendiri mapun orang disekitarnya.

\section{Saran}

Berkaitan dengan penelitian nilai religius dan nilai sosial ini, peneliti berharap penelitian ini tidak hanya dijadikan sebagai bahan bacaan, namun juga bermanfaat untuk diterapkan dalam kehidupan sehari-hari. Selain itu, peneliti juga berharap, penelitian ini dapat menjadi acuan bagi penelitian selanjutnya yang lebih baik lagi. Disarankan penelitian selanjutnya dapat meneliti nilai-nilai pada buku-buku teks bahasa Indonesia yang lain. Dan menambahkan representasi nilainilai lainnya selain nilai religius dan nilai 
sosial seperti pada penelitian dalam Materi Pembelajaran Sastra (cerpen) pada Buku Teks Bahasa Indonesia SMP/MTs Kelas VIII ini.

\section{DAFTAR PUSTAKA}

Jabrohim. 2012. Teori Penelitian Sastra. Yogyakarta: Pustaka Pelajar.

Kurniasih, Imas dan Berlin Sani. 2016. Revisi Kurikulum 2013 Implementasi Konsep dan Penerapan. Jakarta: Kata Pena.

Majid, Abdul dan Dian Andayani. 2012. Pendidikan karakter Perspektif Islam. Bandung:PT Remaja Rosdakarya.
Nurgiyantoro, Burhan. 2010. Teori Pengkajian Fiksi. Yogyakarta:Gadja Mada University Press.

Sujarwa. 2010. Ilmu Sosial dan Budaya Dasar.: Membaca dan Fenomena Sosial Budaya. Yogyakarta: Pustaka Belajar.

Youpika, Fitra dan Darmiyati Zuchdi. 2016. Nilai Pendidikan Karakter Cerita Rakyat Suku Pasemah Bengkulu dan Relevansinya sebagai Materi Pembelajaran Sastra. Jurnal Pendidikan Karakter. Th. VI, No. 1, April, hlm. 48-58. 